\title{
Parasitismo em ser humano por B. microplus (Acari: Ixodidae) em Santa Maria, RS, Brasil
}

\author{
Human parasitism by B. microplus (Acari: Ixodidae), Santa Maria, RS, Brazil

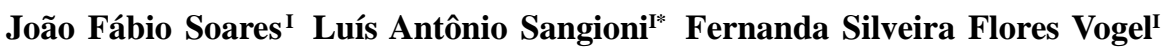 \\ Carlos Flávio Barbosa da Silva ${ }^{\text {II }}$
}

\begin{abstract}
Este trabalho tem como objetivo relatar um caso de parasitismo em ser humano por Boophilus microplus, ocorrido no bairro Alto da Boa Vista, na cidade de Santa Maria, Rio Grande do Sul. Os bovinos, cães e eqüinos apresentavam uma alta carga parasitária. O parasitismo em ser humano foi observado quando dois espécimes estavam fixados no antebraço esquerdo de um indivíduo. Os carrapatos foram identificados como pertencentes à espécime B. microplus. O parasitismo desse carrapato em seres humanos é um achado incomum e pouco relatado em literatura.
\end{abstract}

Palavras-chave: B. microplus, parasitismo, seres humanos, Santa Maria, RS, Brasil.

\section{ABSTRACT}

This article is aimed at reporting a case of parasitism by Boophilus microplus in a human being from Alto da Boa Vista, Santa Maria, Rio Grande do Sul. This area was highly infested by ticks; were observed on cattle, horses, and dogs. The human parasitism was observed when two ticks were fixed to the left forearm of individual. .Ticks were identified as B. microplus. Human parasitism by this species of tick is rather rare and has not been previously reported in the literature.

Key words: B. microplus, parasitism, human, Santa Maria, RS, Brazil

Os carrapatos da espécie Boophilus microplus pertencem à ordem acarina, Família Ixodidae, subfamília Rhipicephalina (FORTES, 2004). Habitam áreas tropicais e subtropicais, encontram-se distribuídos mundialmente desde a latitude de $40^{\circ} \mathrm{N}$ até $30^{\circ} \mathrm{S}$ e estão disseminados por todo o continente americano, exceto no Chile e nos Estados Unidos, onde foram erradicados (FURLONG, 2002). Foram introduzidos no Brasil com as primeiras importações de bovinos zebuínos (Bos indicus), provenientes do continente asiático, de onde o carrapato é originário (HOOGSTRAAL, 1985). Atualmente é encontrado em todos os Estados da federação brasileira (LABRUNA et al., 2005). Tem como características morfológicas: gnatossoma com base hexagonal, rostro e palpos curtos, achatados e rugosos, escudo sem ornamentação, presença de olhos, peritremas arredondados ou ovais, e os machos apresentam duas características marcantes que são: duplo par de placas adanais e extremidade posterior com apêndice caudal. São parasitos obrigatórios, tendo como hospedeiros preferenciais os bovinos, mas, na ausência destes, podem parasitar outros animais tais como eqüinos e cães. Os carrapatos desse gênero fazem todas as ecdises sobre o hospedeiro, sendo classificados como um ixodídeo monoxeno (FORTES, 2004). Assim como em outros gêneros de carrapatos, o B. microplus é um importante vetor de patógenos para os bovinos; dentre eles, está a Babesia spp (HEUCHERT et al, 1999). De acordo

\footnotetext{
'Departamento de Medicina Veterinária Preventiva (DMVP), Centro de Ciências Rurais (CCR), Universidade Federal de Santa Maria (UFSM), Santa Maria, RS, Brasil. Av. Roraima, 1000, Cidade Universitária, Camobi, 97105-900, Santa Maria, RS, Brasil. Email: sangioni@smail.ufsm.br. Autor para correspondência.

"IPrefeitura Municipal de Santa Maria, Vigilância Ambiental. Santa Maria, RS. Brasil.
} 
com MASSARD e FONSECA (2004), a relação parasito/ hospedeiro, o menor grau de especificidade dos carrapatos e os longos períodos de jejum são fatores que favorecem a transmissão de agentes patogênicos. No processo de alimentação, os carrapatos, de forma geral, podem determinar: ação traumática e espoliativa, pela dilaceração de células e tecidos, bem como ação tóxica, pela inoculação de substâncias através da saliva, além de causar anemias, levando a grandes prejuízos econômicos à pecuária brasileira. GRISI et al. (2002) relataram que as perdas econômicas pelo $\boldsymbol{B}$. microplus podem chegar a cerca de dois bilhões de dólares anuais, valores que resultam da diminuição de ganho de peso, de gastos com ectoparasiticidas, da diminuição da produção de leite, da depreciação do couro e de lesões contaminadas predispondo a miíases. O parasitismo de $\boldsymbol{B}$. microplus em seres humanos é um achado incomum, sendo pouco relatado na literatura brasileira. LABRUNA et al. (2005) notificaram o parasitismo de quatro adultos machos de $\boldsymbol{B}$. microplus em pessoas do Estado de Rondônia.

Este trabalho têm como objetivo informar um caso de parasitismo humano por B. microplus ocorrido na cidade de Santa Maria, Rio Grande do Sul, Brasil.

No dia 30 de março de 2006, realizou-se a coleta de fêmeas ingurgitadas de $\boldsymbol{B}$. microplus em uma vaca leiteira, para realização de um teste de biocarrapaticidograma. Duas horas após este procedimento, foram capturados dois carrapatos fixados no antebraço esquerdo de um dos autores desta nota (Figura 1a), tempo este suposto de parasitismo. Os carrapatos encontravam-se a uma distância, um do outro, de aproximadamente cinco centímetros, sendo removidos com o auxílio de uma pinça de dissecação de Cushing lisa, com uma leve torção em sentido antihorário. Os artrópodos foram armazenados em recipiente plástico e mantidos vivos até serem encaminhados ao laboratório de Doenças Parasitárias da Universidade Federal de Santa Maria (UFSM), onde foram conservados em álcool 70\%.

As amostras foram analisadas em um microscópio estereoscópio e fotografadas para posterior auxílio na identificação taxonômica. Após as análises das características anatômicas, foram classificadas segundo ARAGÃO \& FONSECA (1961). A partir disso, foi possível afirmar que os exemplares em questão eram machos adultos que pertenciam à espécie B. microplus (Figura 1b).

Os dois ixodídeos coletados foram encontrados no bairro Alto da Boa Vista, região periférica de Santa Maria, (latitude - 29,68417 e a longitude:- 53,806904), cidade localizada na região central do Rio Grande Sul, a qual possui um clima tropical úmido com uma temperatura média de $19,2^{\circ} \mathrm{C}$, um índice pluviométrico médio de $1.700 \mathrm{~mm}$ e altitude média 113m acima do nível do mar. (PMSM, 2006). Essa localidade apresenta uma densa concentração populacional de baixo poder aquisitivo. A comunidade não apresenta serviço de coleta de esgoto e o lixo é depositado a céu aberto pelos moradores, apesar do serviço de coleta municipal. Foi observada a presença de Riphicephalus sanguineus nas residências da localidade, principalmente aderidos às paredes externas. Os moradores relataram com freqüência este acontecimento. A presença de bovinos de leite infestados pelo B. microplus foi observada na localidade. Estes animais são criados para subsistência e são mantidos em áreas peridomiciliares com vegetação predominante de alecrim do campo (Baccharis dracunculifolia). Além disso, havia eqüinos de tração que coabitavam a mesma pastagem, os quais também apresentavam parasitismo por B. microplus. Foram também encontrados cães errantes parasitados por

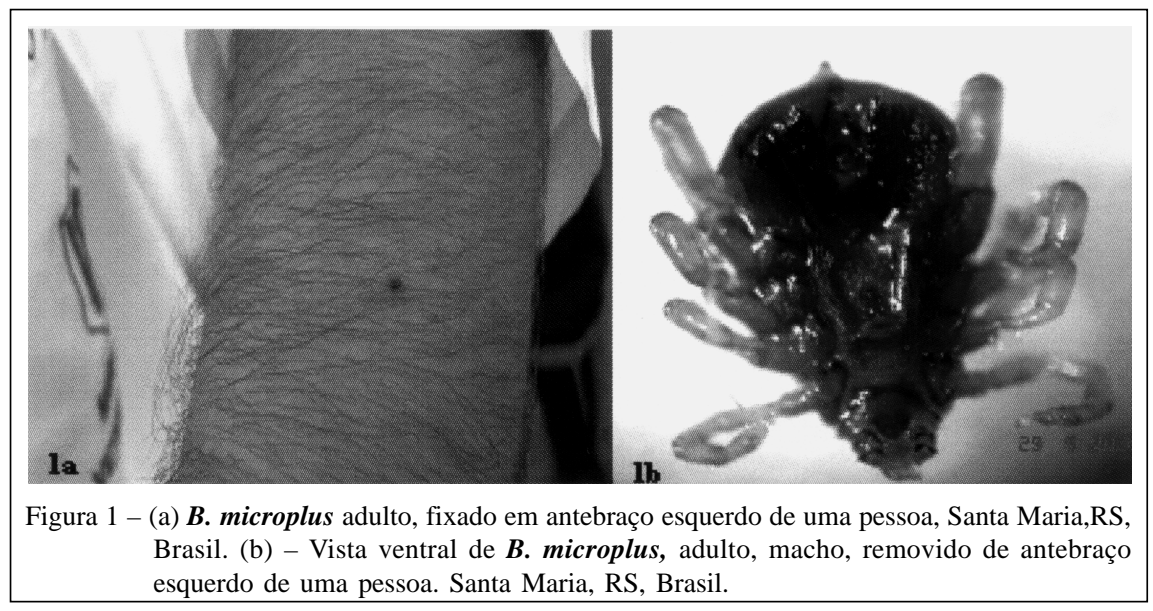

Ciência Rural, v.37, n.5, set-out, 2007. 
carrapatos do gênero Rhipicephalus spp, a espécie comumente relatada nesse animal, em áreas urbanas (LINARDI \& NAGEM, 1973; MASSARD et al., 1981; RIBEIRO et al., 1997). Os eqüinos, bovinos e cães apresentavam-se com alta carga parasitária.

Os carrapatos do gênero Boophilus não costumam habitar regiões urbanas e sim áreas rurais mediante a presença de seu hospedeiro preferencial. Devido à criação de bovinos de leite para subsistência humana em áreas urbanas, estes parasitas passaram a ser mais freqüentemente encontrados nas áreas peridomiciliares, infestando os animais e dispersos na vegetação, de forma de vida livre. As condições ambientais favoráveis para reprodução e desenvolvimento e grande contaminação do meio ambiente torna mais fácil o aparecimento de casos de parasitismo humano (MORENO, 1984; ITO et al., 1998).

O conjunto de fatores encontrados no bairro Alto da Boa Vista, associado às condições climáticas favoráveis, contribuiu para a alta infestação de carrapatos no local. Isso leva a um desequilíbrio na relação parasita/hospedeiro, forçando B. microplus a buscar outros hospedeiros. De acordo com MASSARD \& FONSECA (2004), todas as espécies da família Ixodidae requerem obrigatoriamente sangue de vertebrados para sua evolução e possuem significativo grau de especificidade, podendo utilizar hospedeiros alternativos, incluindo o homem, quando necessário. Apesar de ainda não ser evidenciada a transmissão de patógenos pelo B. microplus, para seres humanos, cabe ressaltar a capacidade vetorial deste carrapato. Casos de parasitismo de $\boldsymbol{B}$. microplus em seres humanos não são comumente relatados mas, devido às condições encontradas por estes ixodideos no bairro Alto da Boa Vista e à sua versatilidade de se adaptar ao meio ambiente, pudemos observar essa ocorrência.

\section{REFERÊNCIAS}

ARAGÃO, H; FONSECA, F. Notas de ixodologia. V. Notas de ixodologia. VIII. Lista e chave para os representantes da fauna ixodológica brasileira. Memórias do Instituto Oswaldo Cruz, 59, n.2, p.115-153, 1961.
FORTES, E. Parasitologia veterinária. 4.ed. São Paulo: Ícone, 2004. 607p.

FURLONG, J. et al. Comportamento e ecologia de larvas do carrapato B. microplus em pastagem de Brachiaria decumbens. Brazilian Journal Veterinary Research Animal Science, São Paulo, v.39, n.4, p.213-217, 2002.

GRISI, L. et al. Impacto econômico das principais ectoparasitoses em bovinos no Brasil. A Hora Veterinária, v.21, n.125, p.8-10, 2002.

HEUCHERT, C.M.S. et al. Sero epidemiological studies on Babesia equi and Babesia caballi infections in Brazil. Veterinary Parasitology, ano 85, p.1-11, 1999.

HOOGSTRAL, H. Argasid and nuttallied ticks as parasites and vectors. Advance Parasitology, v.1, n.24, p.135-238, 1985.

ITO, F.H. et al. Evidência sorológica de brucelose e leptospirose e parasitismo por Ixodídeos em animais silvestres do Pantanal Sul-Mato-Grossense. Ars Veterinary, v.14, p.302-310, 1998.

LABRUNA, M. B. et al. Ticks (Acari: Ixodidae) from the state of Rondônia, western Amazon, Brazil. Systematic \& Applied Acarology, n.10, p.17-32, 2005.

LINARDI, P.M.; NAGEM, R.L. Pulicídeos e outros ectoparasitos de cães de Belo Horizonte e municípios vizinhos. Revista Brasileira de Biologia, v.33, p.529-538, 1973.

MASSARD, C.A. et al. Carrapatos de cães em áreas urbanas e rurais de alguns estados brasileiros. In: CONGRESSO BRASILEIRO DE PARASITOLOGIA, 6., 1981, Belo Horizonte. Anais... Belo Horizonte: SBP, 1981. 201p.

MASSARD, C.L.; FONSECA A.H. Carrapatos e doenças transmitidas, comuns ao homem e aos animais. A Hora Veterinária, v.135, n.1, p.15-23, 2004.

MORENO, E.C. Incidência de ixodídeos em bovinos de leite e prevalência em animais domésticos da Região Metalúrgica de Minas Gerais. 1984. 105f. Dissertação (Mestrado em Ciência Animal) - Curso de Pós-graduação em Medicina Veterinária, UFMG.

PREFEITURA MUNICIPAL DE SANTA MARIA (PMSM) Dados Gerais, Coordenadas geopolíticas, 2006. Capturado em 04 de dez. de 2006. Online. Disponível na internet: http/ /www.santamaria.rs.gov.br/html.

RIBEIRO, V.L.S. et al. Espécies e prevalência das infestações por carrapatos em cães de rua da cidade de Porto Alegre, RS, Brasil. Ciência Rural, v.27, p.285-289, 1997. 